\title{
Integration of Augmented Reality (AR) Technology for Superimposing Digital Content (Images, Sound, Text) Overa Real-World Environment
}

\author{
Subhrajyoti Ranjan Sahu ${ }^{1}$, S. Swetha ${ }^{2}$ \\ ${ }^{1}$ B. Tech.,ECE, Nalanda Institute of Technology, Bhubaneswar. \\ ${ }^{2}$ Assistant Professor, EEE Dept., Vel Tech Multi Tech Dr.Rangarajan Dr.Sakunthala Engineering College, Avadi \\ ${ }^{1}$ subhrajyotiranjan@hotmail.com, ${ }^{2}$ swethasrinivasan4@gmail.com
}

\begin{abstract}
This study discusses AR technology's importance in the business process. This computer-based technology mainly helps to understand the present situation of the real world. This study to identify the authentic result has adopted the secondary data collection methods and descriptive research design to interpret the findings. From this secondary data, this research study has followed the thematic analysis in discussion of the impact of AR technology in the marketplace. In this present time, technical implementation is the most significant role play for the development. Nowadays most of the sectors are using AR technology to analyze real-world conditions. In this present time, technical implementation is the most significant role play for the development. Nowadays most of the sectors are using AR technology to analyze real-world conditions. In this segment, some issues are faced by the society for use of AR technology. This research study can evaluate the development of this technology and improve the use of this technology. This study has found a way to increase the performance of this technology to represent the information of the real world.
\end{abstract}

Keywords - Sensor, algorithm, animation, computerbased, augmented reality

\section{Introduction}

In the present time, digitalization is the most crucial role to play in presenting the real-world environment. In this digitalization, Augmented Reality (AR) is the most effective technology that makes it easy to portray the real-world environment through digital content. AR technology helps to enhance computer-based information and it also affects various sectors. 


\section{Literature review}

\section{Concept of Augmented Reality (AR) technology}

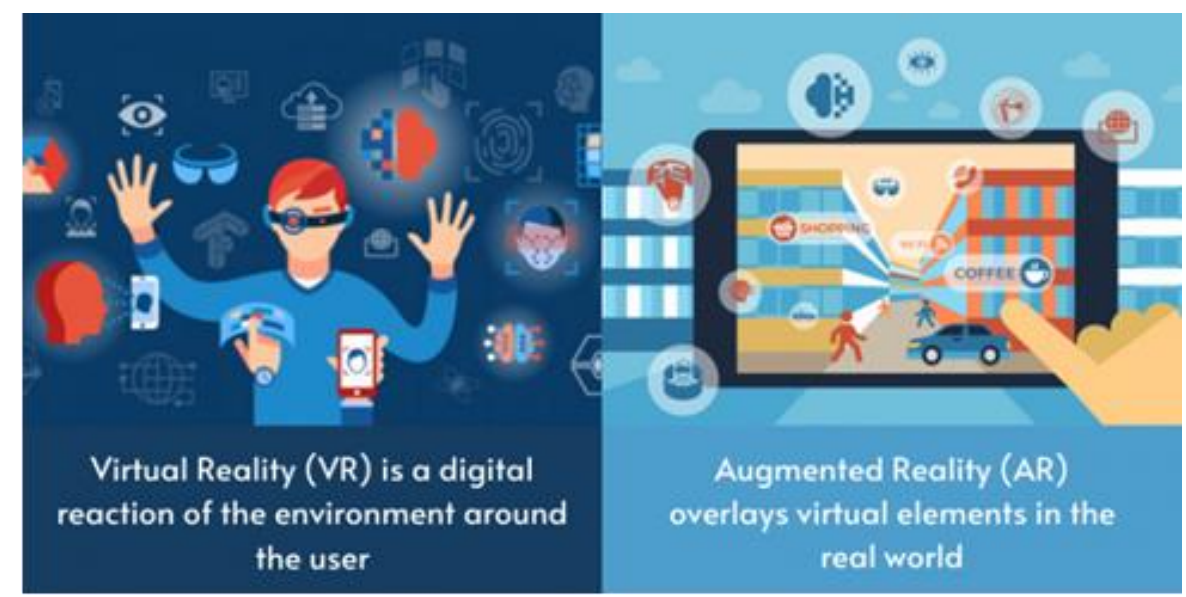

Figure 1: Difference between Augmented Reality and Virtual Reality

(Source: Influenced by Radu and Schneider 2019)

Irwansyah et al. (2017), stated that digitalization and AR technology is the most effective part of analyzing real-world information. AR technology is a piece of the computer-based information analysis process that helps to understand the condition of different sectors. Virtual Reality (VR) and Augmented Reality (AR) is a quite similar computer-based technology that represents the physical environmental condition in the real world. AR technology mainly represents computer-based artificial objects in the real world. In the other words, VR technology makes a computer-based environment through the artificial component. AR technology has used sensors and algorithms to represent real-world information Radu and Schneider (2019). This technology analyzes the images from the viewpoint of the camera and generates the information through digital content. On the other hand, VR uses computer-based sensors and mathematical calculations to represent the artificial environment in a real sense. This technology makes an interactive world effective in a real environment.

\section{Usage of $A R$ in various sectors in developing digital content}

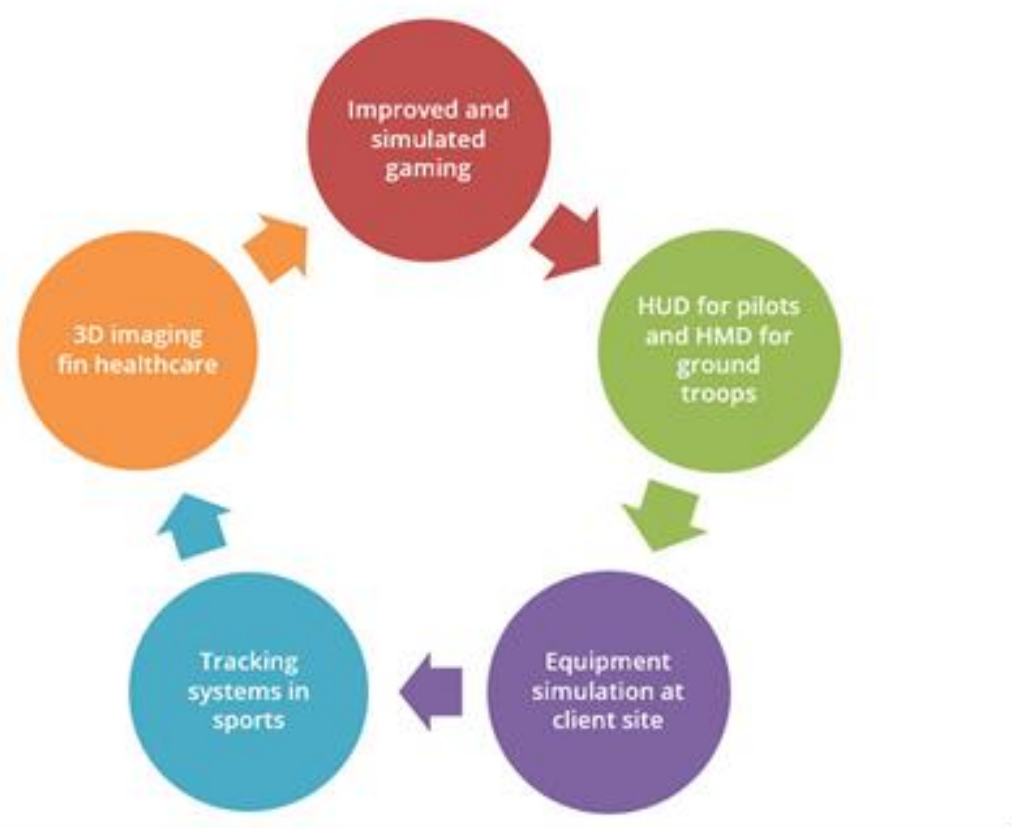

Figure 2: Usage of AR in various sectors 
(Source: Reinhardt et al. 2020)

In this present time, technological implementation is the most significant part of every sector. Different types of sectors are using different types of technologies that help to grow in the marketplace. The AR technology is the most usable technology that helps the business organization to evaluate the present condition of the market and. In this case, medicine, aeronautics and entrepreneurship, manufacturing, and educational sectors mainly use this technology to improve their performance in the marketplace. In the medical sector, the health condition of the country can be represented through this technology (Reinhardt et al. 2020). On the other hand, the manufacturing sector evaluates the market price of their products and can get the chance to improve their manufacturing process. The educational sector is the most effective sector that affects the most in learning and teaching process.

\section{Analysis of use of digital technologies}

In this present time, most of the sector is now using the technology for enhancing their performance skill. Uses of AR technology, the enterprise business sector will cross 117.5 million by 2022 (Clickz, 2019). AR technology is a computer-based information analysis process. This process mainly represents the information of the real world through digital content such as images, animation, sound video, and text. This technological implementation has developed different types of sectors to improve their performance and analyze the information. In recent times, this technological implementation plays a crucial role to develop real-world environment information presentation.

In India, 650 million people use digital technologies which are $50 \%$ of the total population (Clickz 2019). Therefore, in this technological implementation, there are many issues that are found in the real world. This computer-based technology creates a lack of mobile app design and development standards, security and privacy issues, poor quality content, social issues, and the possibility of physical harm. In the real world, most people are now addicted to technology-based app applications. This addiction has dragged people towards these issues (Cabero-Almenara et al. 2019). In this segment, implementation of effective innovation and proper maintenance can resolve these problems and increase the use of AR technology in the market.

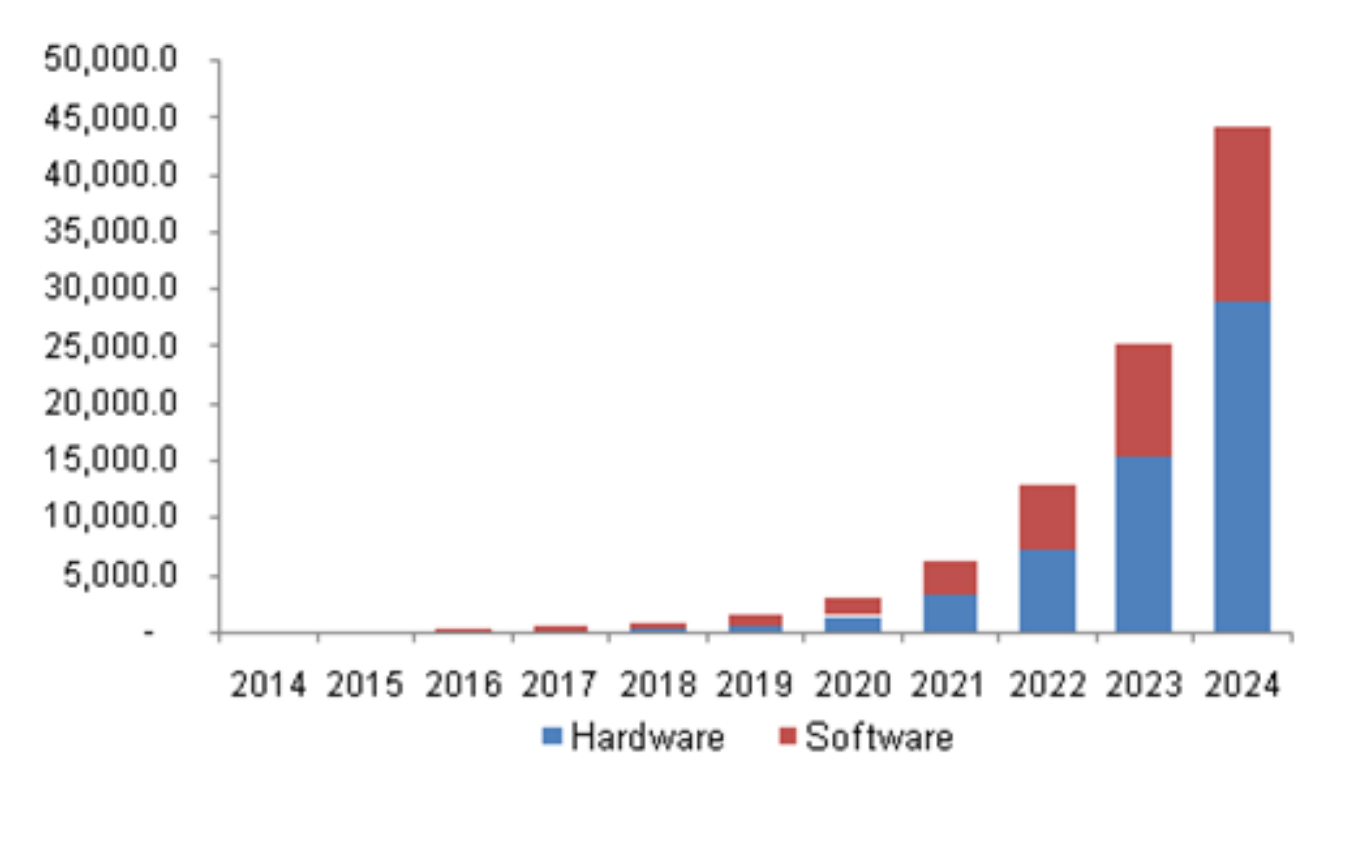

Figure 3: Development of AR technology market value

(Source: Cabero-Almenara et al. 2019)

\section{Evaluation of the use of the natural language of $A R$ in the depiction of images, sounds, and texts of digital content}

In digitalization, technological upgradation is the most effective way that can improve performance and develop the business. In this segment, AR technology has adopted natural language analysis that can help to interpret the present situation of the business. This technology has captured the images through the computer-based camera and analyzes this image by the sound, text, video, and other artificial aspects (Alhogail and Alsabih 2021). This use of natural languages helps to depict the present condition of various sectors. It also helps analyze the data with geographical tools, artificial language, animation, and others. The artificial language can be transformed into linguistic units, texting, and programming that can be further 
transformed into natural language through AR. Therefore, natural language is incorporated with sounds, texts, and sounds especially in digital content to communicate with readers in the form of customers.

\section{Integration of AR technology and digital content (superimposing) in a real environment}

In the information analysis context, AR technology plays the most effective role in this segment. In the statement of Ratajczak et al. (2019), various sectors use this technological implementation to represent the real world view by the computer-based artificial aspects.

Capturing the environment- In this digital technology, the camera has captured the environmental images and those images are mostly described through the computer-based artificial aspects. This technology has represented the 3D view of the real world that can help to analyze the information of the real environment.

Image processing- This AR technology analyzes the images from camera view and makes artificial futures for understanding the present condition of the environment. Computer-Based images help to interpret the situation of the present environment.

Display necessary content- AR technology displays the recent situation of the environment through necessary content such as images, animations, video, audio, and others (Flavián et al. 2019). This technology helps to interpret the present marketing and different sectors analysis through this necessary content.

Superimposing- Superimposing is the most crucial element that can help to interpret the real condition of the environment. This AR technology superimposes artificial features in the real world. On camera-based images, this technology makes the digital content to understand the present marketing situation.

\section{Methods and techniques}

In the research study, the methodology is the most significant tool that helps to find authentic and realistic results. The methodology is of two types one is the data collection process and another is the data analysis process. In the data collection process, there are two ways, primary and secondary data collection processes that help to complete this study. In the pandemic situation, the primary quantitative data collection process could not be possible for the researcher due to lockdown. This research study has followed the secondary qualitative data collection method for completion of this study.

The secondary qualitative data collection process has been conducted with analysis of previous research papers. The researcher has collected qualitative data from the previous journals that were published five years ago. Moreover, the books, authentic websites, online articles, and pdf from research papers have helped the researcher to complete this secondary data collection method in the Covid-19 outbreaks (Elshaikh et al. 2018). In other words, this research study has followed the descriptive research design and positivism philosophy to analyze the findings. This study has conducted a thematic analysis to get the realistic and authentic results of this study.

\section{Result and discussion}

\section{Thematic analysis}

\section{Evolution of AR technology to analyze the real-world environment information}

In the present time, AR technology is the most effective role-play in the business process. The AR mainly helps the business to understand the competitive figures of the market. In traditional methods, the business did not get the chance to analyze the market position and competitive capabilities. After using AR technology, the business sector can identify the issues of the business that mainly creates problems in the development of the business (Cipresso et al. 2018). In this segment, the AR computer-based technology has helped to analyze the present situation of the market and according to that, the business can grow their performance in the marketplace. Computer-based features like audio, video, and images can represent the real-world environment in front of people. AR technology is now using various sectors like medicine, manufacturing, entrepreneurship, and entertainment.

\section{Effects of Ar technology in different sectors for development}

The AR technology helps the business to develop in the marketplace. This technology has provided the various types of businesses the significant real information that can help the business to explore the marketplace. On the other hand, technology sometimes plays a negative impact on society. In this era, people are addicted to technology. In this segment, people mostly use entertainment sites in their daily life. In teenagers, they used this gaming site in their daily life and it sometimes dragged them towards negativity (Sirakaya and Kilic Cakma 2018). Reduce and overcome this negativity these technologies adopt various processes such as natural languages uses and geographical tools. The AR tools help the business to develop in the marketplace.

In the medical sector, AR technology has helped to identify the healthcare structure and performance. In the other words, it also helps to understand the figure of the disease affects. In the Covid outbreak, this technological implementation helps to 
understand the medical needs and decrease the level of the virus. In the Real estate business, this organization helps to understand the present condition of the business and it also helps to develop the business in the marketplace.

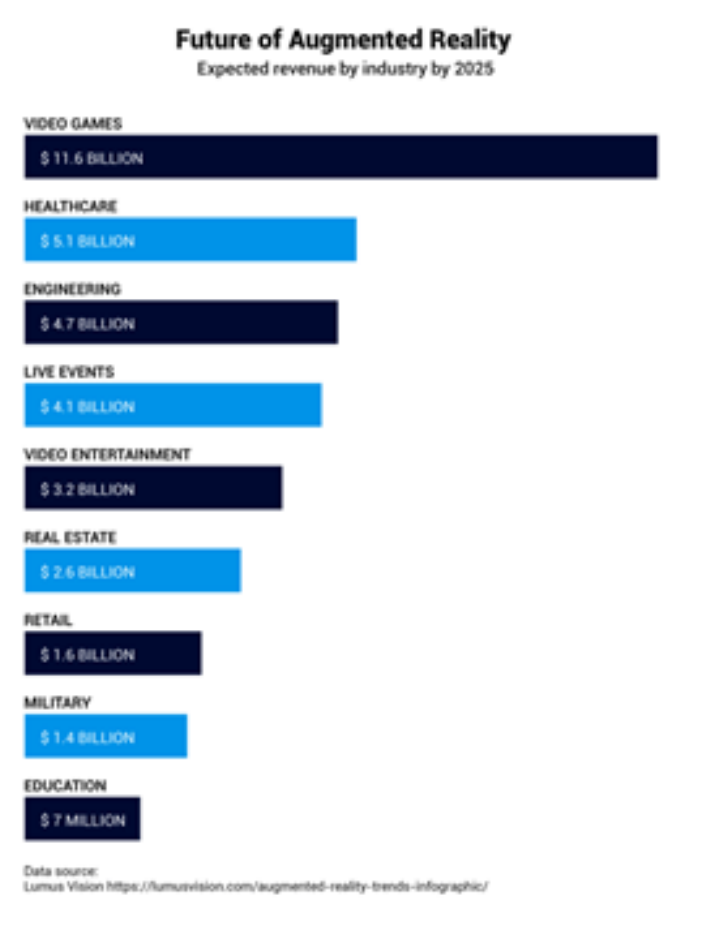

Figure 4: Effects of AR technology in different sectors (Source: Sirakaya and Kilic Cakma 2018)

\section{Increase uses of AR technology in the marketplace}

In the present time, the use of technology is increasing significantly in the marketplace. In development contact, the technology most helps the business to identify the proper way of business. In this segment, AR technology has played the most crucial role in the development of various types of business. This AR technology has helped to represent the real environmental condition through computer-based features. In the past, mainly the medicine, manufacturing and entrepreneurs, and others were using AR technology in their business process (Melton et al. 2020). In the present time, other various business sectors also have started to implement AR technology in their business process. The jewelry, clothing, and toys business sectors also have used this technology to develop their business in the marketplace.

\begin{tabular}{|l|l|}
\hline Sectors & Percentage \\
\hline Furniture & $60 \%$ \\
\hline Clothing & $55 \%$ \\
\hline Groceries & $39 \%$ \\
\hline Makeup & $25 \%$ \\
\hline Jewelry & $25 \%$ \\
\hline Toys & $22 \%$ \\
\hline
\end{tabular}

Table 1: Uses of AR technology in the marketplace

(Source: Influenced by Melton et al. 2020) 
Integrating Researchers to Incubate Innovation

\section{Conclusion}

After all these discussions it can be concluded that AR technology is the most crucial role to play to represent the real-world environment. This technology mainly helps to interpret the present situation of the real marketplace through the computer-based aspects. From this analysis, the various businesses can get the chance to develop their business in the marketplace and understand the competition capabilities. This digital content helps to identify the proper way of business and it also helps to improve the performance of the business. Therefore, everything has been addressed in relation to AR technology that has been used in making and developing digital content.

\section{Reference}

1. Alhogail, A. and Alsabih, A., 2021. Applying Machine Learning and Natural Language Processing to Detect Phishing Email. Computers \& Security, p.102414.

2. Cabero-Almenara, J., Barroso-Osuna, J., Llorente-Cejudo, C. and Fernández Martínez, M.D.M., 2019. Educational uses of augmented reality (AR): Experiences in educational science. Sustainability, 11(18), p.4990.

3. Cipresso, P., Giglioli, I.A.C., Raya, M.A. and Riva, G., 2018. The past, present, and future of virtual and augmented reality research: a network and cluster analysis of the literature. Frontiers in psychology, 9, p.2086.

4. Clickz 2019, Augmented reality examples: 10 industries using AR to reshape business Avaialble at: https://www.clickz.com/augmented-reality-examples-10-industries-using-ar-to-reshape-business/214953/ [Accessed on: 17 ${ }^{\text {th }}$ June 2021]

5. Elshaikh, A.E., Jiao, X. and Yang, S.H., 2018. Performance evaluation of irrigation projects: Theories, methods, and techniques. Agricultural water management, 203, pp.87-96.

6. Flavián, C., Ibáñez-Sánchez, S. and Orús, C., 2019. The impact of virtual, augmented and mixed reality technologies on the customer experience. Journal of business research, 100, pp.547-560.

7. Irwansyah, F.S., Ramdani, I. and Farida, I., 2017. The development of an Augmented Reality (AR) technology-based learning media in metal structure concept. In Ideas for 21 st Century Education (pp. 233-237). Routledge.

8. Melton, A., Damron, T., McCarthy, V. and Rupp, W., 2020. Leveraging technology through crowdfunding to ease barriers of entry into the marketplace. International Journal of Applied Management and Technology, 19(1), p.6.

9. Radu, I. and Schneider, B., 2019, May. What Can We Learn from Augmented Reality (AR)? Benefits and Drawbacks of AR for Inquiry-based Learning of Physics. In Proceedings of the 2019 CHI conference on human factors in computing systems (pp. 1-12).

10. Ratajczak, J., Riedl, M. and Matt, D.T., 2019. BIM-based and AR application combined with location-based management system for the improvement of the construction performance. Buildings, 9(5), p.118.

11. Reinhardt, I.C., Oliveira, J.C. and Ring, D.T., 2020. Current perspectives on the development of Industry 4.0 in the pharmaceutical sector. Journal of Industrial Information Integration, 18, p.100131.

12. Sirakaya, M. and Kilic Cakmak, E., 2018. Effects of augmented reality on student achievement and self-efficacy in vocational education and training. International journal for research in vocational education and training, 5(1), pp.1-18. 